\title{
Premenstrual Syndrome among Female Doctors at King Fahad Armed Forces Hospital: Prevalence and Impact on Work, Jeddah, 2014
}

\author{
Alaa A. Shaheen ${ }^{1}$, Nayef A. Aljohani ${ }^{*}$, Rajaa M. Al-Raddadi² \\ ${ }^{1}$ Family Medicine Department, King Fahd Armed forces hospital, Jeddah, Saudi Arabia. \\ 2Joint program of family and Community Medicine, Jeddah, Saudi Arabia.
}

\begin{abstract}
Background: Premenstrual syndrome (PMS) is a condition, which consists of cyclical physical, behavioral and psychological symptoms, which regularly recurs before period and disappears by the end of menstruation.

Objectives: This study aims to estimate the prevalence, severity of PMS, and its impact on work productivity among a group of female doctors aged between (20-45) at King Fahad Armed Forces Hospital (KFAFH), Jeddah, Saudi Arabia.

Methodology: A cross sectional study with a sample of female doctors ( $\mathrm{N}=177)$ at King Fahad Armed Forces Hospital in Jeddah were included in the study, a self-administered questionnaire distributed among them included sociodemographic questions, premenstrual evaluating questionnaire including the American college of obstetrics \& gynecology (ACOG) criteria, and questions about the effect on work using a valid work assessment questionnaire.

Results: Prevalence of PMS found to be in $50.7 \%$ of female doctors, Most of cases with PMS are in the category borderline to mild (18\%) and mild to moderate (16.3\%). PMS had
\end{abstract}

\section{INTRODUCTION}

It is common for women in reproductive age to experience disrupting symptoms during the days before menstrual period. For some females, the premenstrual symptoms can be severe enough to affect the quality of life by negative effect on behavior and interfering with daily activities. ${ }^{1}$

The tenth revision of the International Classification of Diseases (ICD-10) classify PMS under "Diseases of the genitourinary system: Pain and other conditions associated with female genital organs and menstrual cycle" and labels it as Premenstrual Tension Syndrome (WHO: World Health Organization, 2004). ${ }^{1}$

PMS is a condition, which manifests with distressing physical, behavioral and psychological symptoms, in the absence of organic or underlying psychiatric disease, which regularly recurs during the luteal phase of each menstrual cycle and which disappears or significantly decreases by the end of the menstruation. The degree and type of symptoms can vary significantly from woman to another. Symptoms of PMS are distinguished from normal physiological premenstrual symptoms because they cause significant impairment to activities of daily life. ${ }^{2}$ significant relation with overall work impairment. Saudi female doctors found to be more liable to PMS than non-Saudi.

Conclusion: PMS was prevalent among female doctors at $\mathrm{KFAFH}$, with significant overall work productivity loss.

Key Words: Premenstrual syndrome, Prevalence, Female doctors, Work productivity, Saudi Arabia.

\section{${ }^{*}$ Correspondence to:}

Nayef A. Aljohani, SBFM, ABFM

Senior registrar, Family Medicine department,

King Fahad Armed Forces hospital, Jeddah, Saudi Arabia.

\section{Article History:}

Received: 11-09-2016, Revised: 15-09-2016, Accepted: 18-09-2016

\begin{tabular}{|l|c|}
\hline \multicolumn{2}{|c|}{ Access this article online } \\
\hline Website: & Quick Response code \\
www.ijmrp.com & \\
\hline DOI: & \\
10.21276/ijmrp.2016.2.5.027 & \\
\hline
\end{tabular}

The American College of Obstetricians and Gynecologists (ACOG) published diagnostic guidelines in 2000 for PMS. The diagnosis of PMS can be made if symptoms include at least one of the somatic and affective symptoms following, with a calculated $30 \%$ increase in symptom during the 6 days before menses compared to days 5-10 post menses. These symptom frequency/severity changes need to be documented in a daily diary for 2-3 cycles for diagnosis. In addition, the severity of change should result in some impairment in daily life. ${ }^{1}$

At least one of the following affective and somatic symptoms during the 5 days before menses in2-3 cycles, documented prospectively: affective symptoms include depression, angry outbursts, irritability, anxiety, confusion, and social withdrawal, somatic symptoms include tender/swollen/ painful breasts, abdominal bloating, headache, and water retention/swelling of the extremities. Also for the diagnosis, these symptoms should remit within 4 days of menses onset, not recur until at least day 13 of the subsequent cycle, not be due to any medications, including hormones, drug or alcohol use, be present across at least 2 
cycles as demonstrated by prospective reports and be associated with subjective reports of dysfunction.

Most research on PMS has been done in the West or Far East. To the authors' knowledge, none has been reported from Saudi Arabia regarding the prevalence of PMS among female doctors.

\section{SUBJECTS AND METHODS}

Cross sectional study was implemented among female doctors in reproductive age (20-45 years) working at at King Fahad Armed Forces Hospital in Jeddah, Saudi Arabia. Jeddah is a major city in the western area of Saudi Arabia. It is the largest city in Makkah Province, the largest seaport on the Red Sea, and the second largest city in Saudi Arabia after the capital city, Riyadh, with a population currently at 3.2 million. ${ }^{3}$

The Epi Info 7 program was used for the calculation of the sample size. The sample size was calculated after retrieving data about the number of female doctors at King Fahad Armed Forces Hospital, with the following data; number of female doctors at $\mathrm{KFAFH}$ was 326 , prevalence of PMS: $50 \%$, confidence limitwas $5 \%$, the calculated sample size was 178 female doctors.

Sampling from all departments was taken by the proportionate sample from each department. The total number of female doctors was 326, department were medicine (including ophthalmology, neurology, nephrology, dermatology, endocrinology, cardiology, emergency medicine. surgery, including ENT, obstetrics and gynecology department, dental department, pediatrics, Radiology, and family medicine department, including preventive medicine department.

Women with irregular menstrual cycle were excluded from the study. The study was conducted using 2 Questionnaires, in addition to few questions about socio-demographic data, i.e.; age, marital status, nationality, and questions to assess the presence of psychological disease, and OCP use, which can affect the result of PMS score. The first questionnaire is the PMS Evaluation Questionnaire (PEQ) for assessment of PMS symptoms to confirm the diagnosis and to measure the severity of the symptoms, which includes the ACOG (American college of obstetrics \& gynecology) criteria for the diagnosis of PMS, it includes 18 questions to be answered in a retrospective manner, for 2 consecutive menstrual cycles, the questionnaire was adopted from a website of a gynecologist. ${ }^{4}$

The self-score of PMS symptoms was organized in 2 Columns; Column 1: represented the degree of symptoms in the week before menstrual period. Column 2 included PMS symptoms that scored in the week after menstruation was completed, the questions includes the following symptoms: nervous tension, mood swings, irritability, anxiety, weight gain, swelling of extremities, breast tenderness, headache, craving for sweets, increased appetite, fatigue, palpitations, dizziness or fainting, depression, forgetfulness, crying, confusion, insomnia. Symptoms were rated according to the following scale of 0 to 4 : 0 (ZERO) indicates no occurrence of a particular symptom. 1 (one) indicates that the symptoms are mild, that is they are present but they are not a problem to you. 2 (two) indicates that you consider your symptoms to be moderate in nature. You are experiencing them they are significant but tolerable. 3 (three) indicates that you consider your symptoms to be severe. Where medications are needed or symptoms are bothering to a significant degree and 4 (four) indicates that at some time during this period. There is partial or complete disability. Not able to work, or have to stay at home possibly in bed. Then score was determined by the following calculations: Subtract the total from Column 2 from the total from Column 1. Total Column 2 - total Column $1=$ the PMS score. After having the score, it was classified based on the following ratings: If score is between 0 and $12=$ No PMS. If score is between 13 and $18=$ borderline to mild PMS. If score is between 19 and $25=$ mild to moderate PMS. If score is between 26 and $35=$ moderate to severe PMS. If score is between "36 to $45 "=$ severe PMS. If score is $>45=$ disabling PMS. ${ }^{4}$

The second questionnaire was to test the effect on work, using a validated instrument for assessing work performance; this questionnaire was used in many studies, it is the Work Productivity and Activity Impairment Questionnaire, General Health Version (WPAI: GH). ${ }^{5}$ It yielded three types of scores: Absenteeism (work time missed), presenteesism: (Impairment at work / reduced on-the job effectiveness) and work productivity loss: (Overall work impairment/absenteeism plus Presenteesism). It contains 3 questions, which the scores of them showed the percent of work performance. WPAI outcomes are expressed as impairment percentages, with higher numbers indicating greater impairment and less productivity, i.e., worse outcomes. ${ }^{6}$ As follows: Questions: hours missed due to health problems (Q!), hours actually worked (Q2) an degree health affected productivity while working (Q3). Multiply scores by 100 to express in percentages. Percent work time missed due to health: Q1/(Q1+Q2). Percent impairment while working due to health: Q3/10. Percent overall work impairment due to health: Q1 / (Q1 + Q2)) + [(1 - Q1 / (Q1 + Q2)) * (Q3 / 10)]

It was a self-administered questionnaire, which was completed retrospectively for 2 menstrual cycles. A letter from the general supervisor of the Joint program of Family and community medicine in Jeddah was taken as approval to conduct the study. A verbal consent was taken from each participant upon giving the questionnaire.

Data was entered to own computer by the researcher and analyzed using SPSS version 20.Continuous variables were presented as mean and standard deviation. Categorical variables were presented as percentages. The bivariate analysis was used to identify association between variables. A p value $<0.05$ was considered significant, in addition 95\% Confidence Interval was used to asses significance.

Table 1: Socio-demographic characteristics of the studied group ( $\mathrm{N}=178$ ).

\begin{tabular}{llc}
\hline Variables & $\mathbf{N}(\%)$ \\
\hline Age group & \\
& $20-30$ & $66(37.1)$ \\
Marital status & $112(62.9)$ \\
& Married & $116(65.2)$ \\
& Single & $62(34.8)$ \\
Nationality & & \\
& Saudi & $103(57.9)$ \\
OCS use & Non Saudi & $75(42.1)$ \\
& No & $146(82)$ \\
& Yes & $32(18)$ \\
History of Psychiatric disease & $166(93.3)$ \\
& No & $12(6.7)$ \\
\hline
\end{tabular}




\section{RESULTS}

The study included 178 female doctors. Their Socio-demographic characteristics are described in table (1). Almost two thirds of them were in the age group 31- 45 (62.9\%) and married (65.2\%). More than half of them (57.9\%) were Saudis.

The overall prevalence of PMS was $50.7 \%(\mathrm{~N}=90)$. The severity of PMS was categorized in to 5 groups as shown in figure (1). Most of cases with PMS were in the category borderline to mild $(18 \%)$ and mild to moderate (16.3\%). Disabling is a reflection of PMDD, which represents $(1.7 \%)$ of the total group. Table 2 revealed no significant association between age group and premenstrual syndrome $(p=0.441)$. Also, no significant association was found between marital status and premenstrual syndrome $(p=0.16)$. However, there was a significant association between nationality and premenstrual syndrome $(p=0.044)$ as Saudi female doctors were more liable to PMS than non-Saudis. Regarding history of psychiatric disease, there was no significant association between psychiatric history, use of oral contraceptive pills and premenstrual syndrome.

The effect on work was measured by having 3 scores. Score 1 was the percent of hours missed due to PMS symptoms in 1 week period (luteal phase). Score 2 was the percent of work impairment in 1 week (during the luteal phase). Score 3 was the percent of overall work productivity loss (calculating both score 1 and 2 ).

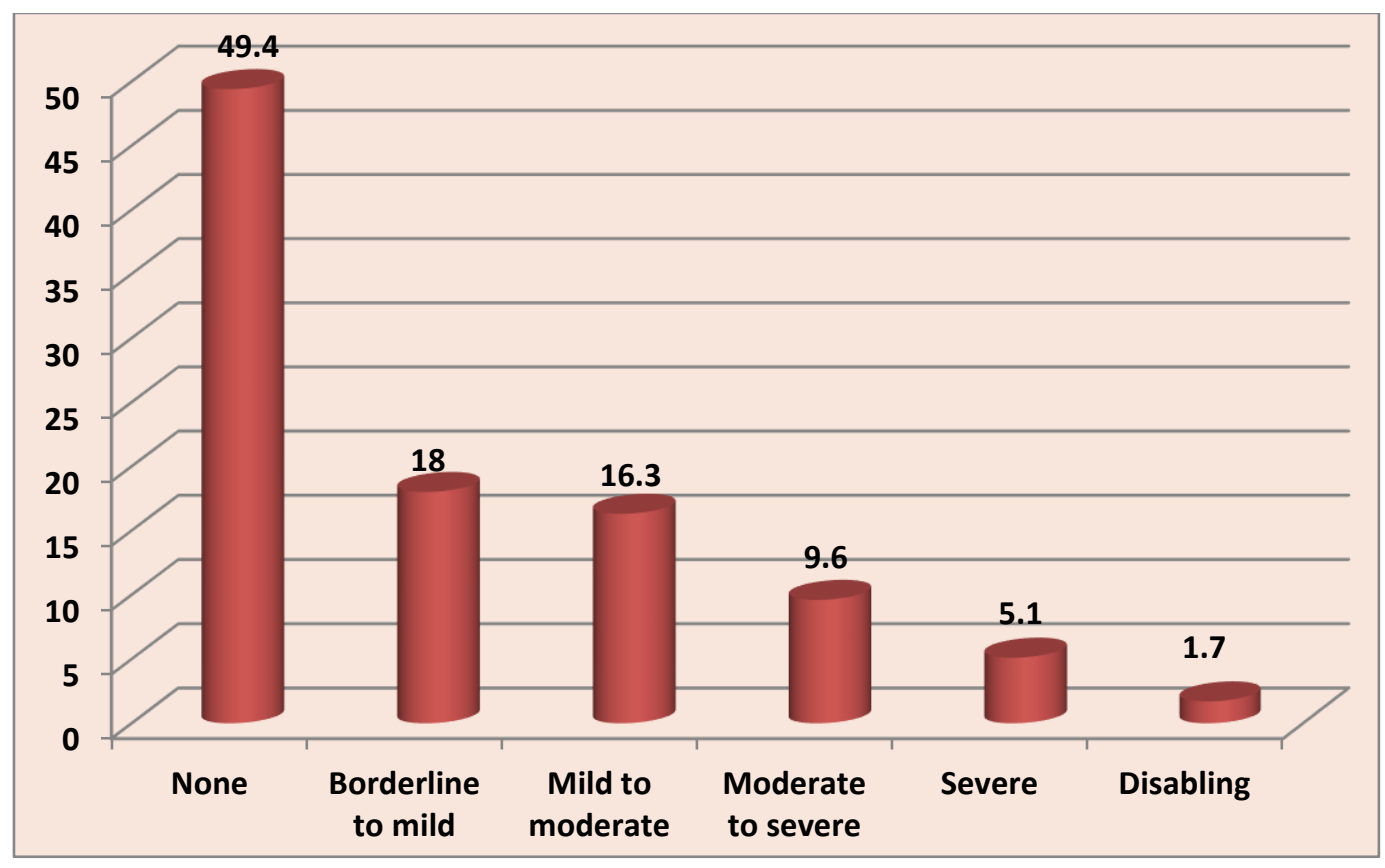

Fig 1: Prevalence and severity of premenstrual syndrome among the studied group.

Table 2: Factors associated with premenstrual syndrome among participants

\begin{tabular}{|c|c|c|c|c|}
\hline \multirow[b]{2}{*}{ Variables } & \multicolumn{2}{|c|}{ PMS } & \multirow{2}{*}{$\begin{array}{c}\text { Chi-square } \\
\text { test }\end{array}$} & \multirow[t]{2}{*}{$P$ value } \\
\hline & No & Yes & & \\
\hline \multicolumn{5}{|l|}{ Age group } \\
\hline $20-30$ & $30(34.1 \%)$ & $36(40.0 \%)$ & 0.666 & 0.441 \\
\hline $31-45$ & $58(65.9 \%)$ & $54(60.0 \%)$ & & \\
\hline \multicolumn{5}{|l|}{ Marital status } \\
\hline Married & 61 (52.6\%) & 55 (47.4\%) & 1.32 & 0.16 \\
\hline Single & $27(43.5 \%)$ & $33(56.5 \%)$ & & \\
\hline \multicolumn{5}{|l|}{ Nationality } \\
\hline Saudi & $45(51.1 \%)$ & $58(64.4 \%)$ & 3.332 & $0.044^{*}$ \\
\hline Non Saudi & $43(48.9 \%)$ & $32(35.6 \%)$ & & \\
\hline \multicolumn{5}{|c|}{ Psychiatric symptoms } \\
\hline No & $82(93.2 \%)$ & $84(93.3 \%)$ & 0.002 & 0.968 \\
\hline Yes & $6(6.8 \%)$ & $6(6.7 \%)$ & & \\
\hline \multicolumn{5}{|l|}{ OCP use } \\
\hline No & $44(72.1 \%)$ & $41(74.5 \%)$ & 0.086 & 0.769 \\
\hline Yes & $17(27.9 \%)$ & 14 (25.5\%) & & \\
\hline
\end{tabular}

OCP: Oral contraceptive pills 
Alaa A. Shaheen et al. Premenstrual Syndrome among Female Doctors

Table 3: Data of the studied group according to PMS severity

\begin{tabular}{|c|c|c|c|c|}
\hline Variables & $\mathbf{N}$ & Score 1 & $\begin{array}{c}\text { Score } 2 \\
\text { Mean } \pm S D^{\star *}\end{array}$ & $\begin{array}{c}\text { Score } 2 \\
\text { Mean } \pm \text { SD*** }\end{array}$ \\
\hline None & 88 & $1.40 \pm 4.36$ & $18.41 \pm 19.17$ & $18.8 \pm 18.10$ \\
\hline Borderline to mild & 32 & $4.96 \pm 10.26$ & $30.31 \pm 18.75$ & $28.36 \pm 17.71$ \\
\hline Mild to moderate & 29 & $4.98 \pm 12.81$ & $44.14 \pm 21.63$ & $41.4 \pm 20.80$ \\
\hline Moderate to severe & 17 & $3.64 \pm 4.85$ & $47.65 \pm 18.55$ & $45.41 \pm 15.57$ \\
\hline Severe & 9 & $6.87 \pm 7.44$ & $57.78 \pm 10.93$ & $54.1 \pm 12.60$ \\
\hline Disabling & 3 & $6.63 \pm 8.84$ & $70.00 \pm 26.46$ & $66.19 \pm 29.90$ \\
\hline${ }^{*} \mathrm{p}=0.069$ & & & .001 & \\
\hline \multicolumn{5}{|c|}{ Score 1: Percent of hours missed from work in 1 week (Luteal phase) } \\
\hline \multicolumn{5}{|c|}{ Score 2: Percent of work Impairment in 1 week (Luteal Phase) } \\
\hline \multicolumn{5}{|c|}{ Score 3: Percent of overall work productivity loss in 1 week } \\
\hline \multicolumn{5}{|c|}{ Table 4: PMS in relation to percent of absence, impairment and overall work loss in 1 week. } \\
\hline \multirow[t]{2}{*}{ Effect on work } & & \multicolumn{2}{|c|}{ PMS } & P Value \\
\hline & & Yes & No & \\
\hline Absence & & $4.96 \pm 10$ & $1.39 \pm 4.39$ & $P=0.002$ \\
\hline Impairment & & $42.11 \pm 21.59$ & $18.4 \pm 19.17$ & $P<0.001$ \\
\hline Work productivity Loss & & $39.62 \pm 20.58$ & $18.07 \pm 18.71$ & $P<0.001$ \\
\hline
\end{tabular}

Regarding the absence score of the studied group according to PMS syndrome, there was higher insignificant score in sever and disabling than other classification. Increasing severity of PMS was highly associated with the impairment of work as there was higher significant score in sever and disabling than other classification. The Scheffe post hoc test showed that there was a significant different of work impairment between those with no PMS compared to all other classifications, except for borderline to mild group, $(P<0.001)$. For the overall work productivity loss (absenteeism plus presenteesism), There was higher significant score in sever and disabling than other classifications.

The overall work impairment was $28.36 \%$ for borderline to mild compared to $66.19 \%$ in the disabling PMS group. The Scheffe post hoc test showed that there was a significant different of overall work productivity loss between those with no PMS compared to all other classifications except for borderline to mild group $(P<0.01)$.

As realized in table (4), there was a significant high score for cases with PMS than those without, regarding absence, impairment and overall work productivity loss. The overall work productivity loss (absenteeism plus presenteesism) was $39.62 \%$ for those with PMS compared to $18.07 \%$ for those without PMS (P value $<0.001$ ).

\section{DISCUSSION}

This study aimed to find the prevalence of PMS among a sample of female doctors at King Fahad Armed Forces Hospital, and to investigate the effect of PMS on work productivity.

In this study, prevalence of PMS was found to be $50.7 \%$ of the studied group. This result is congruent with many international studies, a meta-analysis that included 17 randomized controlled trials found the pooled prevalence to be $47.8 \% .^{7}$ Adewuya reported similar prevalence among university students $(50.1 \%){ }^{8}$ The lowest reported prevalence of PMS was $10.3 \%{ }^{9}$ and the highest found in a prospective study which reported a prevalence of $89.6 \%{ }^{10}$ Studies which included medical students, the prevalence found to be varying from lowest reported prevalence from Saudi Arabia, a cross-sectional study which found the prevalence to be $35.6 \%{ }^{11}$ and51\%12 which is almost the same prevalence found in this study, $67 \%,{ }^{13} 72.1 \%,{ }^{14} 78.5 \%$ from Qassim, Saudi Arabia. ${ }^{15}$

This percentage of prevalence could be attributed to the fact that the female doctors are encountering a great deal of stress from the work load, in addition to social demands, trying to balance between work load and their family needs, particularly that perceived stress was related to PMS in many studies. ${ }^{16}$

Although Sadler et al. concluded that PMS was less in women with less perceived level of stress, and higher level of education. ${ }^{17}$ Similar results were found in a longitudinal study, that higher perceived stress precedes an increased severity of premenstrual symptoms with a recommendation for a stress reduction programs as a non-pharmacological treatment for psychological and physical symptom reduction. ${ }^{18}$

In addition, this significant variance in reported prevalence of PMS could be related to the different diagnosis instruments used to assess presence of PMS, different study population and different study designs.

Classifications of PMS severity varied widely due to different assessment instruments use. Some studies classify it as mildmoderate, moderate- severe, severe, and PMDD, which is the disabling type of PMS. In this study, severity was classifies in to 5 groups, Borderline to mild $32(18 \%)$, Mild to moderate $29(16.3 \%)$, Moderate to severe $17(9.6 \%)$, Severe $9(5.1 \%)$ and Disabling 3 $(1.7 \%)$, the results are consistent with many studies that showed similar percentages for some classifications of severity. A large prospective study by Lothar et al, found PMS severity to be mild $(51.2 \%)$, moderate to severe $(33.2 \%)$, and PMDD $(5.2 \%) .{ }^{10} \mathrm{~A}$ Cross-sectional survey found $(40.8 \%)$ had Mild minimal symptoms, moderate to severe $21.9 \%$, and severe $(8.6 \%) .{ }^{19} \mathrm{Al}-$ Batanony, et al from Qassim, Saudi Arabia, had the same percentage for severe PMS (5.9\%). ${ }^{15}$

The analysis revealed no significant association between age group and premenstrual syndrome $(p=0.441)$, the only study that has similar results of no relation found between age and PMS was reported from UK by Sadler. ${ }^{17}$ However, most of the other studies found a significant relation between age and PMS. 19,20 $^{2}$ 
PMS found to be higher in younger females. ${ }^{12,20}$ Hamaideh found PMS severity increase with older age, ${ }^{17}$ the same results by Adewuya, ${ }^{8}$ and Balaha. ${ }^{11}$

This study showed no significant association between marital status and premenstrual syndrome. This result is similar to one study reported from Iran. ${ }^{20}$ However, many other studies showed significant relation between PMS and marital status. ${ }^{21}$ PMS was reported to be higher in single females..$^{9,22}$

Regarding nationality, it was found that there was a significant association between nationality and premenstrual syndrome. Saudi female doctors were found more liable to PMS than nonSaudi. This is congruent with many studies, Lorraine et al found significant effects of country on symptom severity. ${ }^{19}$ Rizk, et al found PMS more in females with Emirati nationality. ${ }^{23}$

No significant association was found between contraception use among married females and premenstrual syndrome, this is similar to results reported by Chayachinda ${ }^{24}$ and Bakhshani, ${ }^{25}$ while inconsistent with many others, who found OCP to decrease PMS diagnosis or severity as reported by Lopez, ${ }^{26}$ Sadler, ${ }^{17}$ and Maria, who found higher prevalence of the syndrome in women not using any hormonal contraceptive. ${ }^{27}$

There was no significant association between psychiatric history and premenstrual syndrome, this result is consistent with only one study reported from USA by Joyce et al, which found past history of major depression is not related to PMS. ${ }^{28}$ However, the result still in contradiction with all studies relating PMS with previous or current history of Psychiatric illness, they all found that history of Psychiatric illness correlates significantly with PMS diagnosis and increasing severity. ${ }^{11,21.29-35}$ This result could be attributed to the credibility of the participants in answering the question regarding history of psychiatric illness, either due to stigma of the psychiatric illness, or due to the effect of the community in Saudi Arabia, which is less acceptable for the psychiatric illnesses, compared to other communities. Impact on work was measured using 3 scores, for absenteeism, impairment and overall work loss (calculating both absenteeism, impairment)

Regarding the absence score of the studied group according to PMS syndrome. There was no significant relation between PMS and absenteeism, and this result is inconsistent with many other studies that correlates PMS with absence, Lothar et al found that females with moderate-to-severe PMS/PMDD had a higher level of work absenteeism (>8 hours per cycle). ${ }^{10}$ Another prospective assessment of PMS on work found that In workplace, women with PMS reported higher absenteeism rates, and more workdays with $50 \%$ or less reduction in productivity per month. ${ }^{36}$ Others studies had similar conclusion in regard to absence, many were done on university students. ${ }^{13,23,37-39}$ This inconsistency found showing non significance between absenteeism and PMS could be explained by the fact that the attendance rules at the hospital are subjected to a strict measures, where absence would not be allowed based on such subjective symptoms perceived by the employee. In addition, all studies relating PMS with absenteeism also had the same significant results in relating PMS severity with impairment at work, which was the same conclusion found in this study. The mean of work impairment in this study among female doctors with PMS was $42.11 \pm 21.59$ per week, and the impairment was increasing with increased severity of PMS, and this implies a significant burden on the quality of health care provided, as any percent of work impairment of doctors can lead to a considerable consequences.

Among these study limitations, the assessment of PMS symptoms was based on a retrospective recall rather than prospective daily assessment, which is more reliable for diagnosing PMS accurately. In addition, the study was conducted among female doctors only at one health care facility, which may affect generalization of the study results.

In conclusion, PMS is prevalent among female medical doctors at KFAFH and had significant negative impact on work productivity.

\section{REFERENCES}

1. Lustyk MKB, Gerrish WG. Premenstrual syndrome and premenstrual dysphoric disorder: issues of quality of life, stress and exercise. Handbook of Disease Burdens and Quality of Life Measures. Springer; 2010;:1951-75.

2. Panay N. Managing premenstrual syndrome. wohm. 2004 Dec 31;2(3):1-4.

3. Jeddah - Wikipedia, the free encyclopedia [Internet]. en.wikipedia.org. 2013. [cited 2014 Oct 25].

Available from: http://en.wikipedia.org/wiki/Jeddah

4. Allen Lawrence MD. PMS Self Evaluation Questionnaire (PEQ)

Premenstrual Syndrome [Internet]. holisticgynps.com. 2013 [Cited 2014 Oct 25].

Available from: http://www.holisticgynps.com/PremenstrualSyndrome/pms-self-evaluation-questionnaire-peq.html

5. Work Productivity and Activity Impairment Questionnaire: General Health V2.0 (WPAl:GH) [Internet]. reillyassociates.net. 2013 [cited 2014 Oct 25].

Available from: http://www.reillyassociates.net/WPAI_GH.html

6. WPAI GH scoring [Internet]. reillyassociates.net. 2013

Available from: http://www.reillyassociates.net/WPAI_Scoring.html [cited 2014 Oct 25].

7. A DM, K S, A D, Sattar K. Epidemiology of Premenstrual Syndrome (PMS)-A Systematic Review and Meta-Analysis Study. J Clin Diagn Res. 2014 Feb;8(2):106-9.

8. Adewuya AO, Loto OM, Adewumi TA. Pattern and correlates of premenstrual symptomatology amongst Nigerian University students. J Psychosom Obstet Gynaecol. 2009 Jun;30(2):127-32. 9. Tschudin S, Bertea PC, Zemp E. Prevalence and predictors of premenstrual syndrome and premenstrual dysphoric disorder in a population-based sample. Arch Womens Ment Health. 2010 Dec;13(6):485-94.

10. Heinemann LAJ, Minh TD, Heinemann K, Lindemann M, Filonenko A. Intercountry Assessment of the Impact of Severe Premenstrual Disorders on Work and Daily Activities. Health Care for Women International. 2012 Feb; 33(2):109-24. 4.

11. Balaha MH, Amr MAEM, Saleh Al Moghannum M, Saab Al Muhaidab N. The phenomenology of premenstrual syndrome in female medical students: a cross sectional study. Pan Afr Med J. 2010;5:4.

12. Nisar N, Zehra N, Haider G, Munir AA, Sohoo NA. Frequency, intensity and impact of premenstrual syndrome in medical students. J Coll Physicians Surg Pak. 2008 Aug;18(8):481-4.

13. Anandha L S. Priy M, Saraswathi I, Saravanan A, Ramamchandran C. Female Medical Students and its Association with College Absenteeism. Int J Biol Med Res 2011; 2(4): 1011 1016 [Internet]. 2014 Nov 1;:1-6. 
14. Pinar G, Colak M, Oksuz E. Premenstrual Syndrome in Turkish college students and its effects on life quality. Sex Reprod Healthc. 2011 Jan;2(1):21-7.

15. Al-Batanony MA, AL-Nohair SF. Prevalence of Premenstrual Syndrome and Its Impact on Quality of Life among University Medical Students, Al Qassim University, KSA. Public Health Research. Scientific \& Academic Publishing; 2014;4(1):1-6.

16. Rasheed P, Al-Sowielem LS. Prevalence and predictors of premenstrual syndrome among college-aged women in Saudi Arabia. Ann Saudi Med. 2003 Oct 31;23(6):381-7.

17. Sadler C, Smith H, Hammond J, Bayly R, Borland S, Panay N, et al. Lifestyle Factors, Hormonal Contraception, and Premenstrual Symptoms: The United Kingdom Southampton Women's Survey. J Womens Health (Larchmt). 2010 Mar;19(3):391-6.

18. Gollenberg AL, Hediger ML, Mumford SL, Whitcomb BW, Hovey KM, Wactawski-Wende J, et al. Perceived stress and severity of perimenstrual symptoms: the BioCycle Study. J Womens Health (Larchmt). 2010 Apr 30;19(5):959-67.

19. Dennerstein L, Lehert $P$, Bäckström TC, Heinemann K. Premenstrual symptoms -- severity, duration and typology: an international cross-sectional study. Menopause Int. 2009 Sep;15(3):120-6.

20. Delara M, Borzuei H, Montazeri A. Premenstrual Disorders: Prevalence and Associated Factors in a Sample of Iranian Adolescents. Iran Red Crescent Med J. 2013 Aug 5;15(8):695700.

21. Hamaideh SH, Al-Ashram SA, Al-Modallal H. Premenstrual syndrome and premenstrual dysphoric disorder among Jordanian women. J Psychiatr Ment Health Nurs. 2013 Feb 28;21(1):60-8.

22. Adigüzel $H$, Taşkin EO, Danaci AE. [The symptomatology and prevalence of symptoms of premenstrual syndrome in Manisa, Turkey]. Turk Psikiyatri Derg. 2006 Dec 31;18(3):215-22.

23. Rizk DEE, Mosallam M, Alyan S, Nagelkerke N. Prevalence and impact of premenstrual syndrome in adolescent schoolgirls in the United Arab Emirates. Acta Obstet Gynecol Scand. 2006;85(5):589-98.

24. Chayachinda C, Rattanachaiyanont M, Phattharayuttawat S, Kooptiwoot S. Premenstrual syndrome in Thai nurses. J Psychosom Obstet Gynaecol. 2008 Sep;29(3):199-205.

25. Bakhshani NM, Hosseinbor M, Shahraki Z, Sakhavar N. Premenstrual Syndrome Symptomatology among Married Women of Fertile Age based on Methods of Contraception (Hormonal versus Non-Hormonal Methods of Contraception). GJHS. 2013 Nov 10;6(2).

26. Lopez LM, Kaptein AA, Helmerhorst FM. Oral contraceptives containing drospirenone for premenstrual syndrome. Cochrane Database Syst Rev. 2011 Dec 31;2:CD006586-6.

27. Silva CMLD, Gigante DP, Carret MLV, Fassa AG. [Population study of premenstrual syndrome]. Rev Saude Publica. 2006 Feb;40(1):47-56.

28. Bromberger JT, Schott LL, Matthews KA, Kravitz HM, Randolph JF Jr, Harlow S, et al. Association of past and recent major depression and menstrual characteristics in midlife. Menopause: The Journal of The North American Menopause Society. 2012 Sep;19(9):959-66.

29. Yang J, Joe S-H, Lee M-S, Kim S-H, Jung I-K. Survey of premenstrual symptom severity and impairment in Korean adolescents: premenstrual dysphoric disorder, subthreshold premenstrual dysphoric disorder and premenstrual syndrome. Asia Pac Psychiatry. 2014 May 31;6(2):135-44.

30. Forrester-Knauss C, Stutz EZ, Weiss C, Tschudin S. The interrelation between premenstrual syndrome and major depression: results from a population-based sample. BMC Public Health. BioMed Central Ltd; 2011 Oct 12;11(1):795.

31. Accortt EE, Kogan AV, Allen JJB. Personal history of major depression may put women at risk for premenstrual dysphoric symptomatology. Journal of Affective Disorders. 2013 Sep 25;150(3):1234-7.

32. Cheng S-H, Shih C-C, Yang Y-K, Chen K-T, Chang Y-H, Yang $Y-C$. Factors associated with premenstrual syndromedA survey of new female university students. Kaohsiung Journal of Medical Sciences. Published by Elsevier Taiwan LLC; 2013 Feb 1;29(2):100-5.

33. Cirillo PC, Passos RBF, Bevilaqua MCDN, López JRRA, Nardi AE. Bipolar Disorder and Premenstrual Syndrome or Premenstrual Dysphoric Disorder Comorbidity: A Systematic Review. Revista Brasileira de Psiquiatria. 2012 Dec;34(4):467-79. 34. Hong JP, Park S, Wang H-R, Chang SM, Sohn JH, Jeon HJ, et al. Prevalence, correlates, comorbidities, and suicidal tendencies of premenstrual dysphoric disorder in a nationwide sample of Korean women. Soc Psychiatry Psychiatr Epidemiol. 2012 Dec;47(12):1937-45.

35. Firoozi R, Kafi M, Salehi I, Shirmohammadi M. The Relationship between Severity of Premenstrual Syndrome and Psychiatric Symptoms. Iran J Psychiatry. 2012;7(1):36-40.

36. Dean BB, Borenstein JE. A prospective assessment investigating the relationship between work productivity and impairment with premenstrual syndrome. J Occup Environ Med. 2004 Jun 30;46(7):649-56.

37. Tolossa FW, Bekele ML. Prevalence, impacts and medical managements of premenstrual syndrome among female students: cross-sectional study in College of Health Sciences, Mekelle University, Mekelle, northern Ethiopia. BMC Women's Health; 2014 Mar 29;14(1):52-2.

38. Omu FE, Al-Marzouk R, Delles H, Oranye NO, Omu AE. Premenstrual dysphoric disorder: prevalence and effects on nursing students' academic performance and clinical training in Kuwait. J Clin Nurs. 2011 Oct;20(19-20):2915-23.

39. Karout N, Hawai SM, Altuwaijri S. Prevalence and pattern of menstrual disorders among Lebanese nursing students. East Mediterr Health J. 2012 Mar 31;18(4):346-52.

\section{Source of Support: Nil. Conflict of Interest: None Declared.}

Copyright: (c) the author(s) and publisher. IJMRP is an official publication of Ibn Sina Academy of Medieval Medicine \& Sciences, registered in 2001 under Indian Trusts Act, 1882.

This is an open access article distributed under the terms of the Creative Commons Attribution Non-commercial License, which permits unrestricted non-commercial use, distribution, and reproduction in any medium, provided the original work is properly cited.

Cite this article as: Alaa A. Shaheen, Nayef A. Aljohani, Rajaa M. Al-Raddadi. Premenstrual Syndrome among Female Doctors at King Fahad Armed Forces Hospital: Prevalence and Impact on Work, Jeddah, 2014. Int J Med Res Prof. 2016; 2(5):135-40. 